Key Words:

Stress corrosion cracking

304L Stainless Steel

ASTM G36

Retention: Permanent

\title{
ASSESSMENT OF RESIDUAL STRESSES IN SRS AND HANFORD 3013 INNER AND CONVENIENCE CANS
}

\author{
J. I. Mickalonis
}

MARCH 2009

Savannah River National Laboratory Savannah River Nuclear Solutions

Aiken, SC 29808 


\section{DISCLAIMER}

This work was prepared under an agreement with and funded by the U.S. Government. Neither the U. S. Government or its employees, nor any of its contractors, subcontractors or their employees, makes any express or implied:

1. warranty or assumes any legal liability for the accuracy, completeness, or for the use or results of such use of any information, product, or process disclosed; or

2. representation that such use or results of such use would not infringe privately owned rights; or

3. endorsement or recommendation of any specifically identified commercial product, process, or service.

Any views and opinions of authors expressed in this work do not necessarily state or reflect those of the United States Government, or its contractors, or subcontractors.

Printed in the United States of America

Prepared for

U.S. Department of Energy 
SRNL-STI-2009-00121, REVISION 0

\section{REVIEWS AND APPROVALS}

J. I. Mickalonis, Author, Materials Science \& Technology

Date

P. E. Zapp, Peer Reviewer, Materials Science \& Technology

Date

K. A. Dunn, Program Lead, Materials Science \& Technology

Date

G. T. Chandler, Manager, Materials Application \& Process Technology, Materials Science \& Technology

N. C. Iyer, Manager, Materials Science \& Technology

Date

J. W. McClard, MIS Representative, M\&O Engineering

Date

- ii - 


\section{TABLE OF CONTENTS}

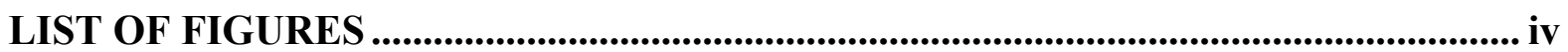

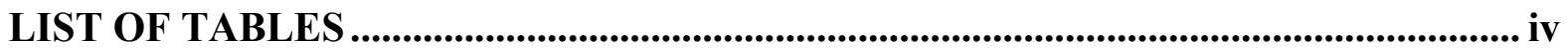

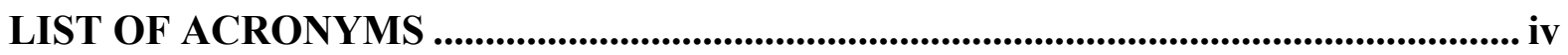

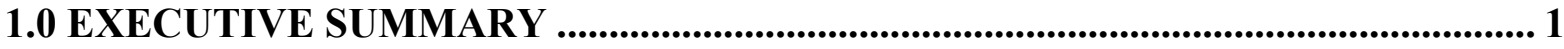

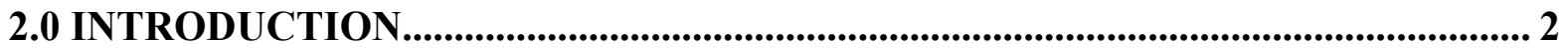

3.0 EXERIMENTAL DESCRIPTION AND TASK ACTIVITIES ............................... 3

4.0 BOILING MAGNESIUM CHLORIDE TEST RESULTS ....................................... 6

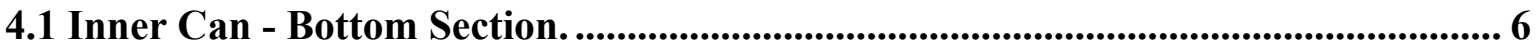

4.2 Inner Can - Welded Top ..................................................................................................... 7

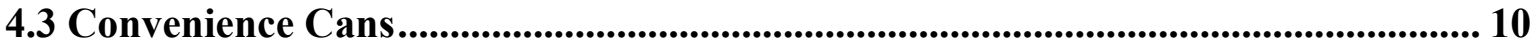

4.4 304L Teardrops........................................................................................................................ 12

5.0 CALCIUM CHLORIDE TEST RESULTS.......................................................... 13

5.1 Inner Can - Welded Top .................................................................................. 13

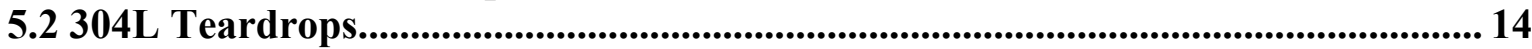

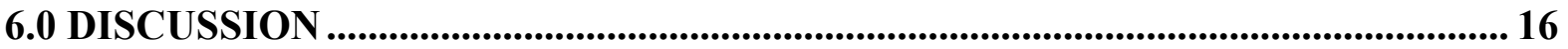

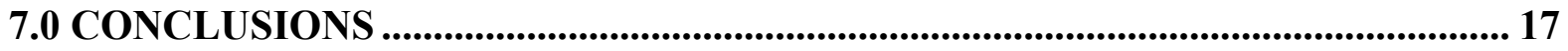

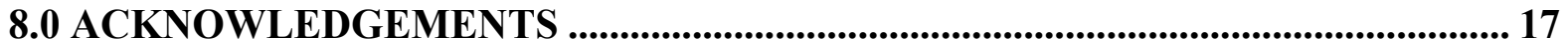

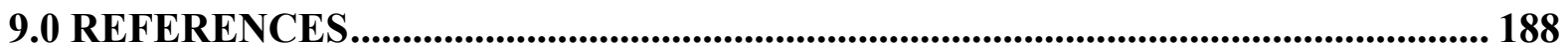




\section{LIST OF FIGURES}

Figure 1. 3013 inner can prior to testing in boiling magnesium chloride ........................... 4

Figure 2. Test setup for calcium chloride at $100{ }^{\circ} \mathrm{C}$ and boiling magnesium chloride tests in 3013 inner cans

Figure 3. Dye penetrant testing of 3013 inner can bottoms: (A) Inner can \#2, (B) Inner can \#4

Figure 4. 3013 inner can top after exposure to boiling magnesium chloride: (A) can exterior showing crack parallel to the weld and numerous cracks perpendicular to the weld; (B) can interior with sidewall and plug cracks ........................................ 8

Figure 5. 3013 inner can top after exposure to boiling magnesium chloride solution showing pit associated with cracking in sidewall ........................................... 9

Figure 6A. 3013 inner can exposed to vapors of boiling magnesium chloride solution: can exterior showing small surface cracks and heavy pitting ..................................... 9

Figure 6B. 3013 inner can exposed to vapors of boiling magnesium chloride solution: interior can crevice spread open showing small cracks

Figure 7. Hanford convenience can showing leaking water drop at crack which occurred from testing in a boiling magnesium chloride solution

Figure 8A. SRS Convenience can after exposure to boiling magnesium chloride solution: can exterior with axial cracks in sidewall

Figure 8B. SRS Convenience can after exposure to boiling magnesium chloride solution: can exterior bottom with radial cracks

Figure 9. 304L teardrops after exposure to boiling magnesium chloride ........................ 12

Figure 10. 3013 inner cap welded top tested a with $40 \%$ calcium chloride solution at $100{ }^{\circ} \mathrm{C}$

Figure 11. 304L Teadrops tested in $40 \%$ calcium chloride solution at $100{ }^{\circ} \mathrm{C}$ for: (A) 188 hours; (B) 194 hours; and (C) 220 hours

Figure 12. 304L Teadrop with cracks after exposure to the vapors from a $40 \%$ calcium chloride solution at $100^{\circ} \mathrm{C}$

Table 1. Test Matrix

\section{LIST OF TABLES}

Table 2. Boiling Magnesium Chloride Test Results for 3013 Cans 3

$\mathrm{DE}$

Destructive Evaluation

EDM

HAZ

Electro-discharge Machining

KAMS

Heat Affected Zone

LLNL

K-Area Material Surveillance

SCC

Lawrence Livermore National Laboratory

SRNL

Stress Corrosion Cracking

Savannah River National Laboratory 


\subsection{EXECUTIVE SUMMARY}

Chloride stress corrosion cracking (SCC) is a plausible corrosion mechanism for the stainless steel 3013 containers during their lifetime for plutonium material storage if sufficient electrolyte is present within the container [1]. Contributing factors for SCC, such as fabrication and welding residual stresses, are present in the 3013 cans. Convenience and inner cans from both Hanford and SRS are made by a flow form process, which cold works the stainless steel during fabrication. Additionally, the inner cans also are sealed at the can top with a closure weld to the sealing plug. Only SRS and Hanford were tested since moisture levels were significant for SCC.

As part of the 3013 corrosion plan for FY09, testing in a boiling magnesium chloride solution was performed on actual 3013 convenience and inner cans to determine if the residual stresses were sufficient for the initiation and propagation of SCC [2]. Additional testing in a $40 \%$ calcium chloride solution was also performed on 304L stainless steel SCC coupons, i.e. stressed teardrop-shaped samples (teardrops), and an inner can welded top to provide comparative results and to assess the effect of residual stresses in a less aggressive environment.

The testing performed under this task consisted of 3013 inner and convenience cans and 304L teardrops exposed to a boiling magnesium chloride solutions per ASTM G36 and a $40 \%$ calcium chloride solution at $100{ }^{\circ} \mathrm{C}$ following the guidance of ASTM G123.

Cracking occurred in all can types including the inner can bottom and welded top and the bottoms of the SRS and Hanford convenience cans when exposed to the boiling magnesium chloride solution at $155^{\circ} \mathrm{C}$. Cracking occurred at different times indicative of the residual stress levels in the cans. 304L teardrops cracked in the shortest time interval and therefore provide a conservative estimate for can performance. Testing in a $40 \%$ calcium chloride solution at $100{ }^{\circ} \mathrm{C}$ demonstrated that cracking occurs in a less aggressive environment but at significantly longer times than in the boiling magnesium chloride. Vapor space cracking was also found to occur in the inner can welded top exposed over the boiling magnesium chloride solution and on 304L teardrops exposed over a hot calcium chloride solution. 


\subsection{INTRODUCTION}

Chloride stress corrosion cracking (SCC) is a plausible corrosion mechanism for the stainless steel 3013 containers during their lifetime for plutonium material storage [1]. The three factors necessary for SCC occurrence are a susceptible material, a corrosive environment and a tensile stress. The stress can be either an applied load or residual stress, which results from fabrication or welding processes. For the 3013 containers, both fabrication and welding residual stresses may be present. The convenience and inner cans are made by a flow form process, which cold works the stainless steel during fabrication. The inner cans also are sealed at the can top with a closure weld to the sealing plug. These residual stresses may exceed the yield strength of the SS and are particularly problematic in the weld heat affect zone (HAZ) where microstructure also contributes to the potential for SCC.

This task was limited to SRS and Hanford cans because packaging conditions resulted in some cans with moisture contents approaching the level at which SCC may occur. Rocky Flats and Lawrence Livermore National Laboratory (LLNL) packaged their plutoniumbearing materials at moisture levels below 14\% relative humidity [12], which are levels where SCC is not expected. Future packaging at Los Alamos National Laboratory and LLNL have strictly controlled procedures that will limit packaging moisture levels.

As part of the 3013 corrosion plan for FY09, testing in a boiling magnesium chloride solution was performed on actual 3013 convenience and inner cans to determine if the residual stresses were sufficient for the initiation and propagation of SCC [2]. Additional testing in a $40 \%$ calcium chloride solution was also performed on 304L stainless steel SCC coupons, i.e. stressed teardrop-shaped samples (teardrops), and an inner can welded top to provide comparative results and to assess the effect of residual stresses in a less aggressive environment.

Testing in boiling magnesium chloride is an accepted ASTM standard practice for assessing the effects of material properties (composition, surface finish, microstructure, heat treatment, etc.) and stress condition on susceptibility to chloride SCC [3]. This method had been previously used to demonstrate that sufficient residual stress existed for SCC in the HAZ of the outer 3013 can [4]. The outer cans are made of 316L stainless steel. After a 48-hour test period, cracking was observed in the two HAZs of the outer container, the closure weld and the fabrication weld, which joins the base to the cylindrical sidewall sections. The cracks were found to grow perpendicularly from the welds in both the can sidewall and the top plug. In no case did the magnesium chloride solution leak from the cans during testing, which indicated the tightness of the cracks.

The boiling magnesium chloride solution is a severe environment that may not agree with actual exposure, such as the 3013 cans in storage at KAMS [3, 5]. Corrosion tests for determining SCC susceptibility have been developed for less aggressive environments where test results correlate better with actual industrial service. The test environments include a boiling acidified sodium chloride solution (ASTM G123 [6]) and a 40\% calcium chloride solution at $100^{\circ} \mathrm{C}$. Since cracking in the small scale corrosion tests occurred with salts 
containing calcium chloride, the $40 \%$ calcium chloride was chosen to demonstrate that cracking occurs in 3013 cans in a less aggressive environment [7]. The calcium chloride solution was used for testing an inner can welded top and 304L teardrops to assess SCC susceptibility, to provide comparative results for teardrops and actual cans, and to attempt to measure crack propagation rates.

\subsection{EXPERIMENTAL DESCRIPTION AND TASK ACTIVITIES}

The testing performed under this task consisted of 3013 inner and convenience cans and 304L teardrops exposed to a boiling magnesium chloride solutions per ASTM G36 and a $40 \%$ calcium chloride solution at $100^{\circ} \mathrm{C}$ following the guidance of ASTM G123. Table 1 gives the test matrix for this task. Post-test analyses were primarily visual evaluations documented by photography. Limited metallographic examinations and dye penetrant testing were performed also.

Table 1. Test Matrix

\begin{tabular}{|c|c|c|}
\hline Test Sample & Boiling $\mathbf{M g C l}_{\mathbf{2}}-\mathbf{1 5 5}^{\circ} \mathbf{C}$ & $\mathbf{4 0} \% \mathbf{C a C l}_{\mathbf{2}}-\mathbf{1 0 0}{ }^{\circ} \mathbf{C}$ \\
\hline Inner Can - Bottom & $\mathrm{X}$ & $\mathrm{X}$ \\
\hline Inner Can -Welded Top & $\mathrm{X}$ & \\
\hline Hanford Convenience & $\mathrm{X}$ & $\mathrm{X}$ \\
\hline SRS Convenience & $\mathrm{X}$ & $\mathrm{X}$ \\
\hline 304L Teardrops & $\mathrm{X}$ & \\
\hline
\end{tabular}

ASTM G36 is an accelerated aggressive test and involves exposing test samples to a boiling magnesium chloride solution for a user-defined test period. Per the standard, a boiling temperature of $155{ }^{\circ} \mathrm{C}$ was used which occurs in a $45 \%$ magnesium chloride solution. In previous testing with 3013 outer cans following this standard practice, cracking was observed after a 48-hour test period [4], so the same time period was used for this testing. When cracking occurred earlier and the solution started to leak from the can, the test was ended.

The test cans were 3013 inner cans and both SRS and Hanford convenience cans. The cans were cut by electro-discharge machining (EDM) into top and bottom pieces. Most pieces were cut with an $8-\mathrm{cm}$ sidewall height. The inner cans had been used for previous testing and had holes in the bottom and side walls. These holes were filled with weld filler metal and then ground flat. The holes on the bottom were not completely filled so a small 0.25 "diameter hole on the solution side was present. Figure 1 shows an inner can bottom prior to testing; note the weld-filled sidewall hole, which is indicated by an arrow.

The cans were tested by using them as the container for the boiling magnesium chloride solution. Glass tops were made for each can type. The tops had ports for a condenser, thermometer and thermocouple. The remainder of the set up consisted of a hot plate and secondary glass container in which the can sat on top of the hot plate. A test was conducted by placing the required quantities of magnesium chloride and water into the can, covering with the glass top, heating until boiling was initiated and the temperature was stabilized, which was typically around $157^{\circ} \mathrm{C}$. Additional water was added to adjust the temperature 
down to $155^{\circ} \mathrm{C}$. The thermocouple was attached to a temperature controller, which was used overnight as a safety precaution against a runaway temperature.

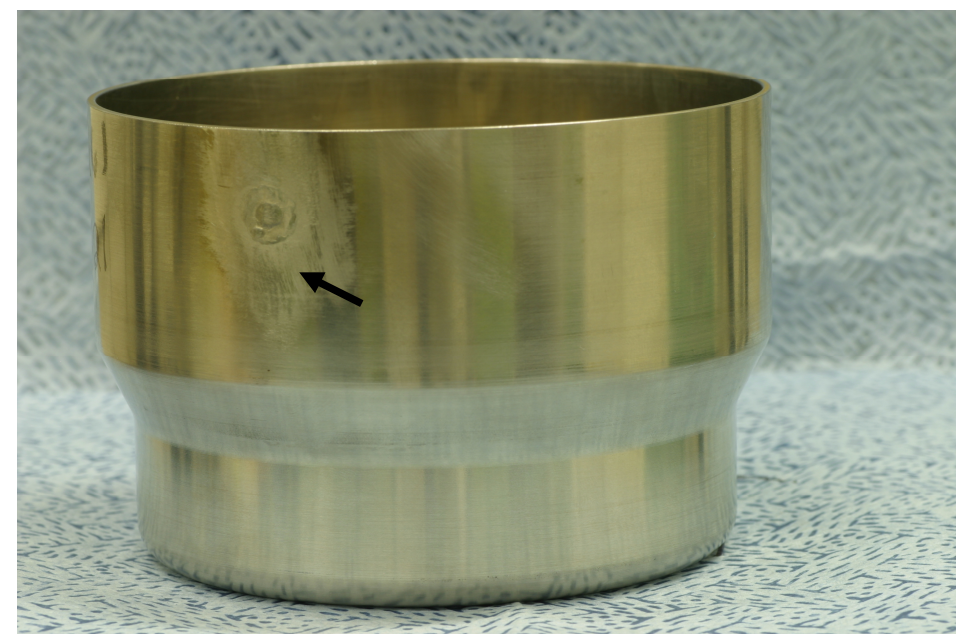

Figure 1. 3013 inner can prior to testing in boiling magnesium chloride; arrow indicates the weld-filled hole in can sidewall.

A recurring problem with the operation of this test was the loss of moisture from the test solution. This water loss led to changes in the boiling temperature of the solution. This loss occurred mostly during testing of the inner cans because the glass tops were difficult to fit for a tight seal. The moisture loss was through the glass top/can junction. Various methods were used to minimize this water loss but were not successful. Water additions were frequently required to maintain the temperature at $155^{\circ} \mathrm{C}$. Overnight the temperature controller maintained the temperature, but continual water loss raised the solution boiling temperature so boiling generally ceased. Water additions were needed to bring the boiling temperature back to $155^{\circ} \mathrm{C}$.

At the conclusion of a test, a can was filled with water to determine if leaking occurred from both know and unknown cracks. If leaking did not occur the cans were tested with dye penetrant to determine if cracking had occurred.

Since some of the DE inner cans have shown corrosion in the vapor space over the plutonium-oxide-bearing materials, an inner can top was suspended over a boiling magnesium chloride solution to evaluate if SCC would occur in the welded top. The solution and can top were enclosed in a glass container. The remainder of the set up was similar to that for the cans above. The test was run for five days.

$304 \mathrm{~L}$ teardrops, identical to the small-scale corrosion test samples $\left(1 / 16^{\prime \prime}\right.$ thick $\times 3 / 4$ " wide $\times$ 4" length) [7], were also exposed to boiling magnesium chloride solutions for comparison with the can test results. These results may assist in correlating teardrop results from the small-scale testing with expected can performance. Small-sized teardrops $\left(1 / 16^{\prime \prime}\right.$ thick $\times 1 / 2$ " wide $\times 21 / 2$ " length) were also tested since these smaller samples were being considered for use in future small-scale tests. Additional standard teardrops were also tested without welds. 
The samples were purchased from Metal Samples Inc. Munford AL. The teardrops were suspended in boiling $\left(155^{\circ} \mathrm{C}\right)$ magnesium chloride solutions contained in glass containers. Tests were run until the teardrops cracked.

Attempts were made to fabricate teardrop-shaped samples out of strips cut from the 3013 inner cans for comparison to the 304L teardrops. However, the strips cracked during forming around a 0.5 " mandrel, which is indicative of the amount of cold work in the cans. The size of the mandrel was the same as that used to make the 304L teardrops. A consecutive series of decreasing mandrel sizes (1.5", 1 " and 0.5 ") was also tried but the samples always cracked. Some strips, which were also welded, cracked too when bent around the mandrel.

The calcium chloride test was performed to determine crack initiation and propagation rates in an environment that was more similar to the small scale corrosion test environment where SCC was observed. The test solution was 40\% (5.03 M) calcium chloride. The test temperature was $100{ }^{\circ} \mathrm{C}$ (boiling point of this solution is approximately $120^{\circ} \mathrm{C}$ ). The teardrops were used to measured crack propagation. Three samples of the standard and small-sized teardrops were immersed in the solution and removed sequentially at increasing times. A fourth sample of both sizes was used to measure the open-circuit potential during the course of the test. Potential changes were being used as a possible indicator for the start of cracking. The teardrops had wires attached near the joining weld. The weld and wire connection were then mounted in an epoxy. A saturated calomel electrode was used as a reference and was held at room temperature using a water-cooled salt bridge. Two samples of each size were also suspended over the solution in the vapor space. The tests were run in a glass cell equipped with a condenser, thermometer, and thermocouple. The glass cell sat in a heating mantle which was controlled by a temperature controller and thermocouple. The test was conducted for approximately nine days.

The test for the inner can welded top was set up similarly to the boiling magnesium chloride tests; Figure 2 shows this setup. Testing was conducted at $100^{\circ} \mathrm{C}$ until the can cracked.

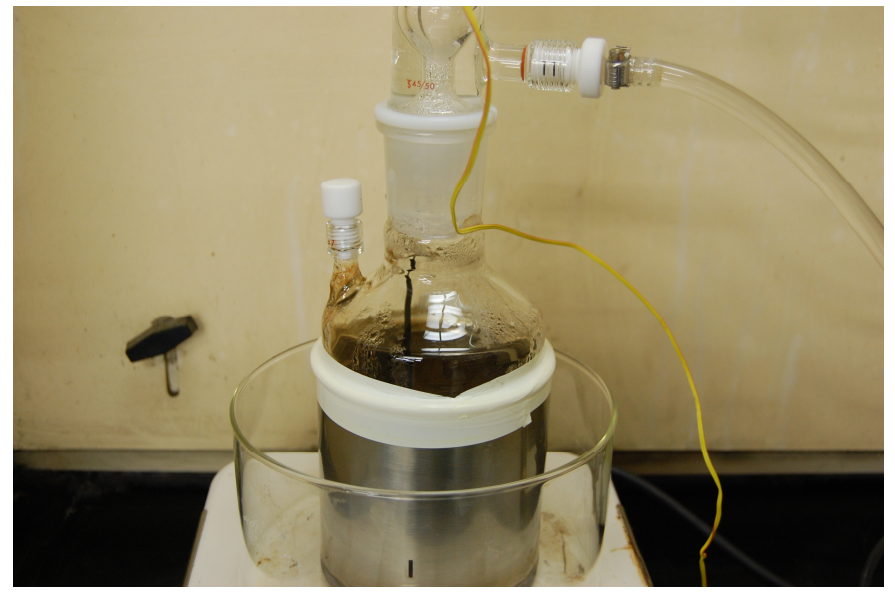

Figure 2. Test setup for calcium chloride at $100{ }^{\circ} \mathrm{C}$ and boiling magnesium chloride tests in 3013 inner cans. 


\subsection{BOILING MAGNESIUM CHLORIDE TEST RESULTS}

Cracking occurred in all can types including the inner can bottom and welded top and the bottoms of the SRS and Hanford convenience cans. All the test results for the 3013 cans are summarized in Table 2. Multiple tests were performed on the inner can bottom because of the variable results and the complications from the previous testing holes, which were located in the bottom and sidewall as shown in Figure 1. Two inner can tops were also tested for reproducibility. Availability of convenience cans limited testing to a single test.

Table 2. Boiling Magnesium Chloride Test Results for 3013 Cans

\begin{tabular}{|l||c|l|}
\hline \multicolumn{1}{|c|}{ Can Section } & Hours in Test & \multicolumn{1}{c|}{ Crack Locations } \\
\hline Inner Can \#1 - Bottom $-6.5 \mathrm{~cm}$ & 5 & $\begin{array}{l}\text { EDM cut rim } \\
\text { Bottom drilled hole } \\
\text { Circumferential }\end{array}$ \\
\hline Inner Can \#4 - Bottom - 11 cm & 24 & $\begin{array}{l}\text { Sidewall hole } \\
\text { Bottom drilled hole } \\
\text { Circumferential }\end{array}$ \\
\hline Inner Can \#2- Bottom - $8 \mathrm{~cm}$ & 48 & $\begin{array}{l}\text { Sidewall hole } \\
\text { Bottom drilled hole } \\
\text { Circumferential and axial in sidewall }\end{array}$ \\
\hline Inner Can \#3 - Bottom - $\mathrm{cm}$ & 48 & $\begin{array}{l}\text { EDM cut rim } \\
\text { Bottom drilled hole }\end{array}$ \\
\hline No sidewall hole & 2 & Perpendicular to weld \\
\hline Inner Can \#3 - Top & 3.5 & Parallel and perpendicular to weld \\
\hline Inner Can \#1 - Top & 120 & $\begin{array}{l}\text { Small cracks in crevice perpendicular to } \\
\text { weld }\end{array}$ \\
\hline Inner Can \#2 - Top - Vapor & 5.5 & Axial in sidewall and radial in bottom \\
\hline SRS Convenience Can & 48 & Circumferential and axial in sidewall \\
\hline Hanford Convenience Can & 1.3 & Through wall near weld \\
\hline 304 L Teardrops & & \\
\hline
\end{tabular}

\subsection{INNER CAN - BOTTOM SECTION}

The cracking in 3013 inner can bottoms occurred in several locations but not all cans cracked at each location. The cans all had a hole drilled in the bottom, which was sealed with weld metal. The cans cracked at this location and generally leaked. Two cans had a hole in the sidewall, which was formed during a can puncture test. Cracking also occurred at these holes. Cracks from both these holes followed an irregular circuitous path.

Initially, the inner can bottoms were not thought to have cracked at other locations, such as the areas where the diameter size changes. During the post-test water leakage checks, leaks were only noted from the bottom and the sidewall drilled hole. Dye penetrant testing was used on the can interiors and cracking was located in two cans (can \#4 and \#2) as shown in 
Figure 3. Inner can \#4 (Figure 3B) had a circumferential crack which was through wall along a short length. Inner can \#2 (Figure 3A) had both circumferential and axial cracks but all cracks were not through wall. The variability in cracking for the inner can bottom may be associated with differences in can fabrication as well as testing variability. It is important to note that one inner can bottom section did not have any other cracks than those associated with the drilled holes.

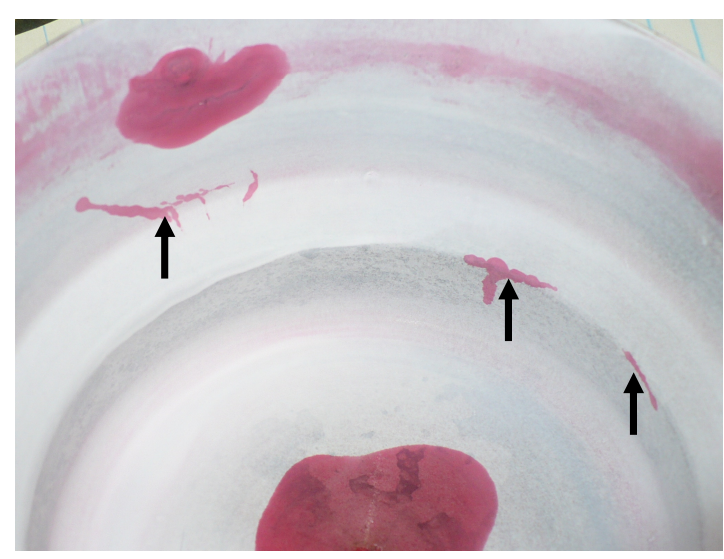

(A)

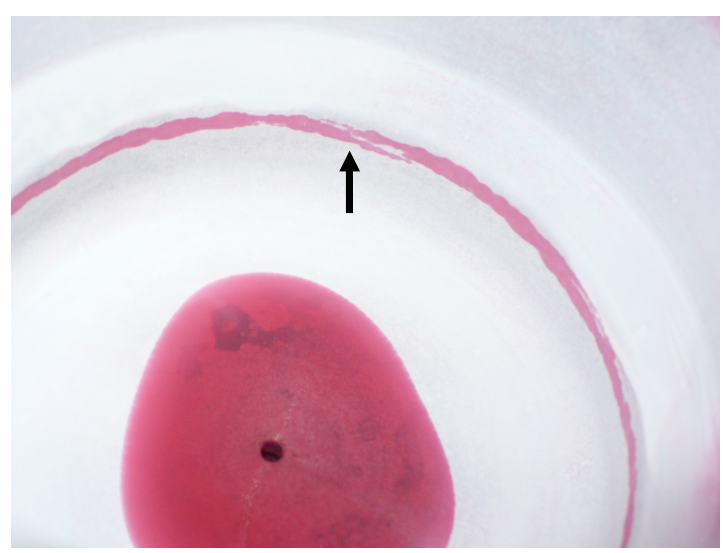

(B)

Figure 3. Dye penetrant testing of 3013 inner can bottoms: (A) Inner can \#2, (B) Inner can \#4. Pink lines indicate crack locations and pink spots are the drilled hole locations. Arrows indicate cracks not associated with drilled holes.

\subsection{INNER CAN - WELDED TOP}

The inner can welded-tops cracked quickly in the boiling magnesium chloride with times of 2 and 3.5 hours. Testing was stopped because of a large amount of leaking from the cracks. The cracks were both along the weld, perpendicular to the weld along the can axis, and radially from the plug perimeter (Figure 4). The crack along the weld occurred in the can which was exposed for the longer time and covered approximately $60 \%$ of the perimeter. The cracks in the sidewall were greater in number than those in the plug. Additionally, the cracks were longer (5-9 $\mathrm{mm}$ in length) and more apparently through wall. The radial and perpendicular cracks were straight unlike the cracks generated at the drilled holes. 


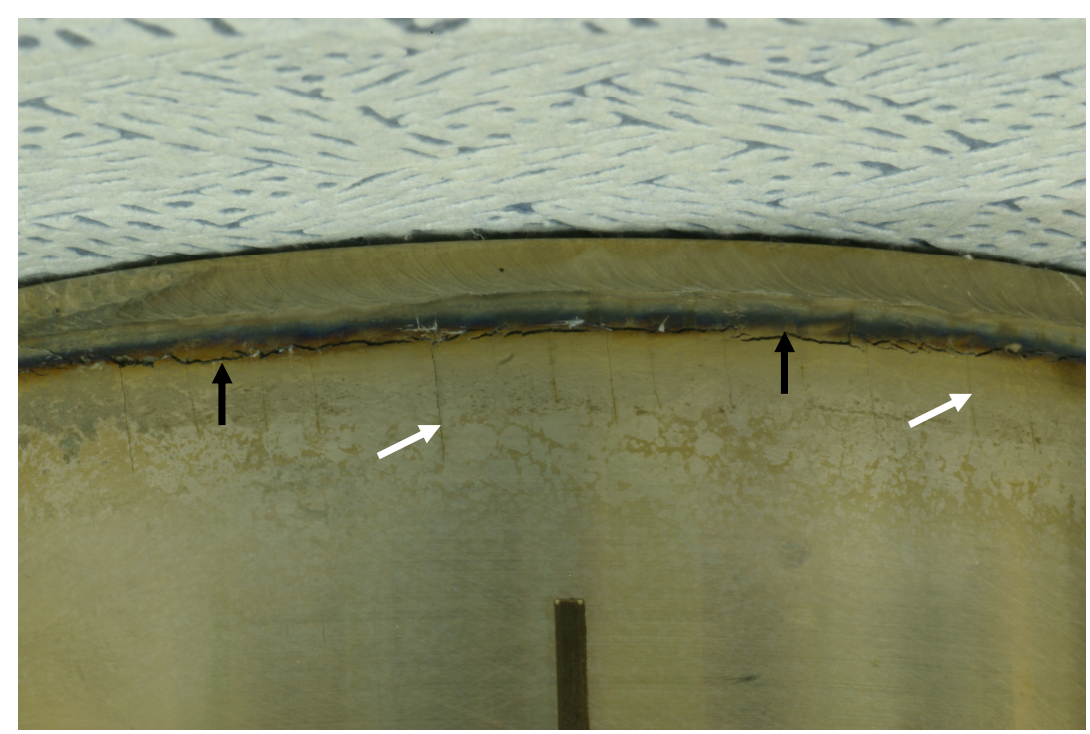

(A)

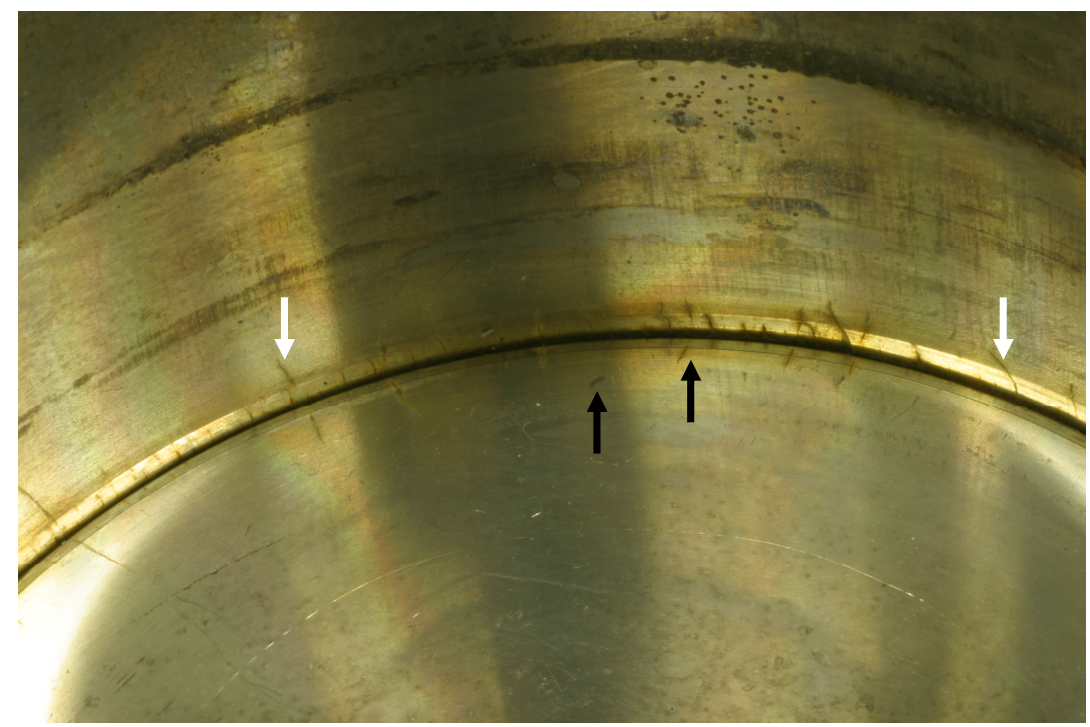

(B)

Figure 4. 3013 inner can top after exposure to boiling magnesium chloride: (A) can exterior showing crack parallel to the weld and numerous cracks perpendicular to the weld (white arrows - perpendicular cracks, black arrows - parallel crack), (B) can interior with sidewall and plug cracks (white arrows - perpendicular cracks, black arrows - radial cracks).

The welded top of inner can \#1 was sectioned to look within the crevice formed by the top plug and sidewall. Large pits were found in the plug and sidewall. In many cases these pits were associated with the observed cracks as shown in Figure 5. The small cracks had multiple orientations relative to the pits. The growth of these cracks indicated the complex stress state near the weld. 


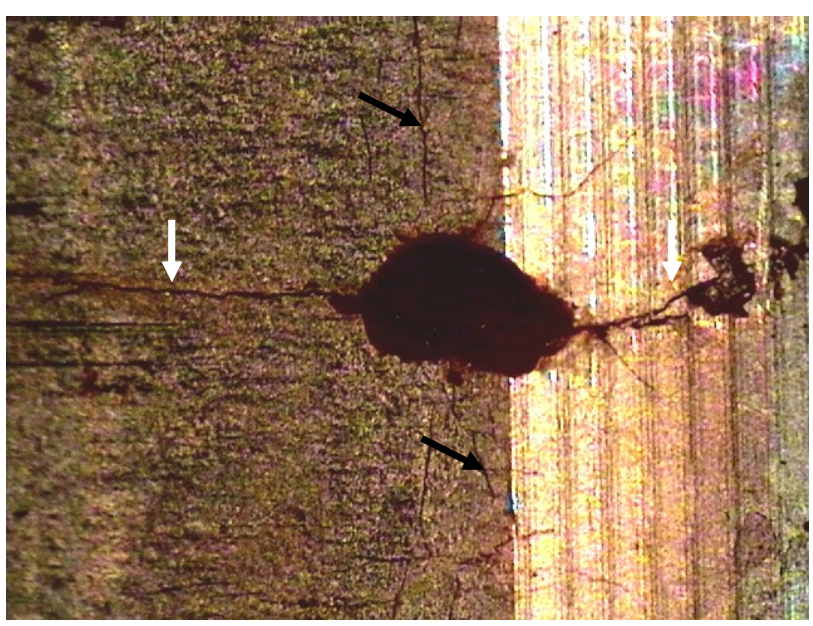

Figure 5. 3013 inner can top after exposure to boiling magnesium chloride solution showing pit associated with cracking in sidewall. Arrows indicate axial (white) and circumferential (black) cracks.

The inner can top exposed to the vapors of the boiling magnesium chloride solution had small cracks in both the sidewall and top after five days of exposure. The cracks were not through wall. On the exterior, the can suffered principally from general and pitting corrosion (Figure 6A).

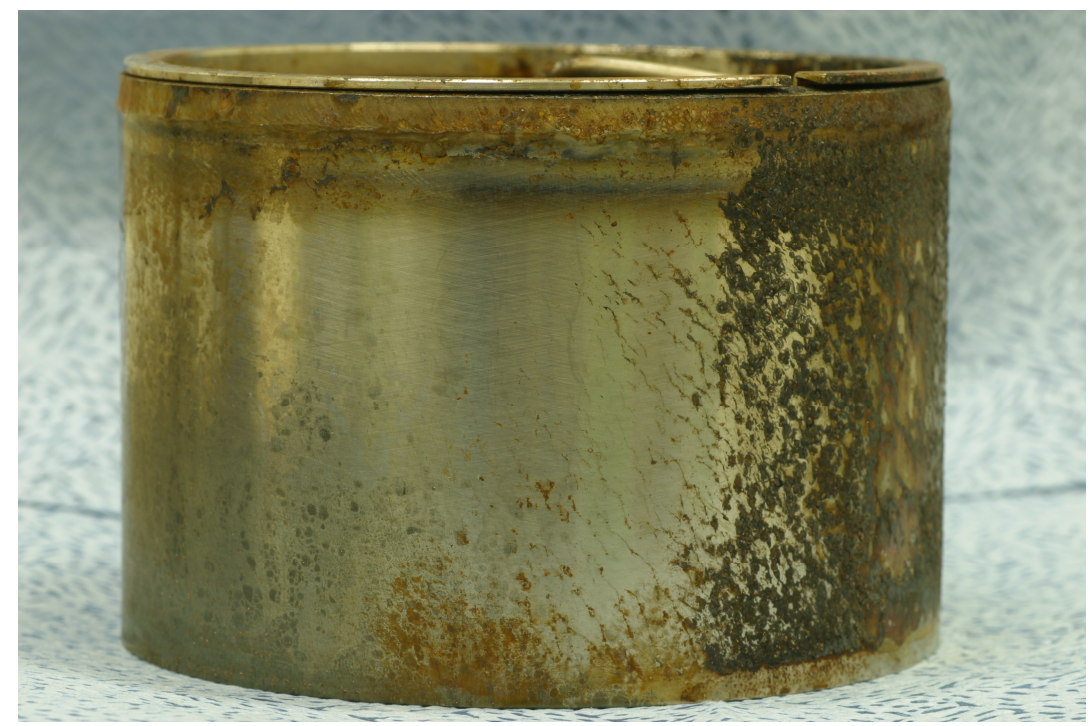

(A)

Figure 6A. 3013 inner can exposed to vapors of boiling magnesium chloride solution: can exterior showing small surface cracks and heavy pitting. 


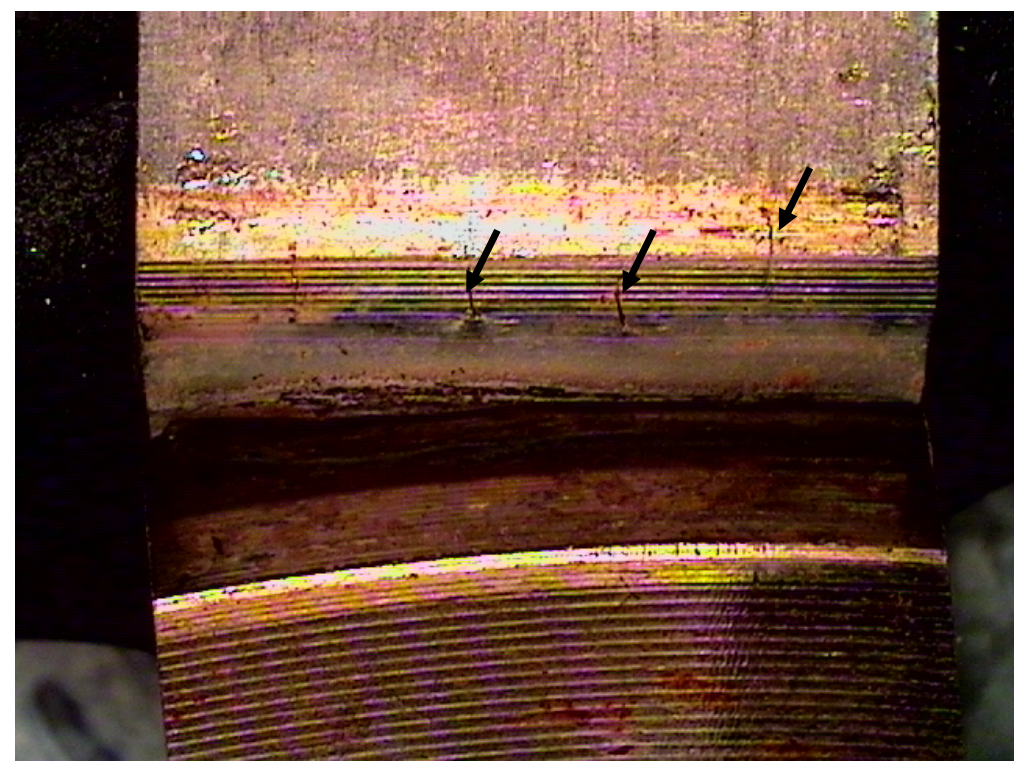

(B)

Figure 6B. 3013 inner can exposed to vapors of boiling magnesium chloride solution: interior can crevice spread open showing small cracks (arrows indicate cracks).

Some small surface cracking was observed on the exterior surface. The crack locations and orientations appeared to follow presumed vapor flow around the can. The can was exposed at a slight angel to the boiling solution surface. The can interior showed only a small degree of corrosion although the surface was wetted during testing.

The can was sectioned by EDM so that the interior surface of the crevice could be inspected for pitting and cracking since the use of dye penetrant testing was unsuccessful. Several pieshaped sections were cut from the can. The crevice was revealed by spreading it open. Inside the crevice large pits and small axial cracks were located. When the crevice was split open the cracks opened up as shown in Figure 6B. Cracks were also found on the side of plug.

\subsection{CONVENIENCE CANS}

Both the SRS and Hanford convenience cans cracked during testing. The SRS can leaked during testing so the test was stopped. The Hanford can did not leak so it was exposed to the boiling magnesium chloride solution for the entire 48-hour test period. More cracks were found in the Hanford can, which was probably associated with this longer test period. The cracks in the Hanford can were all located in the bottom portion with the angled sidewall (Figure 7). Most of the cracks appeared to curve as they approached the parallel sidewall region of the can. No cracks were found on the bottom of the can. When the Hanford can was leaked checked with water after the test, only two small drops formed on the sidewall (Figure 7). After tapping the can on the counter, which loosened the cracks, water was found to leak from most of the cracks. 


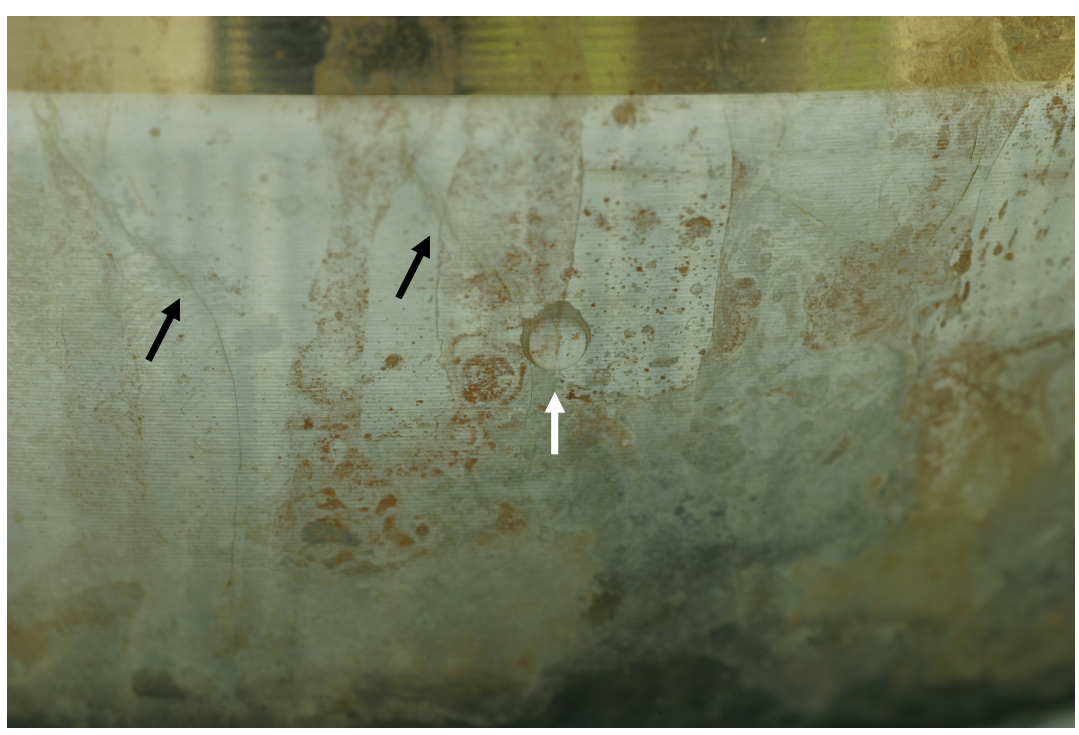

Figure 7. Hanford convenience can showing leaking water drop at crack which occurred from testing in a boiling magnesium chloride solution. White arrow indicates water drop and black arrows point to cracks.

Six cracks were found on the SRS can in the region of diameter size change. These cracks all appeared to have bifurcated and stopped growing at the top of this diameter transition section (Figure 8A). This result was similar to the Hanford convenience can. The SRS can also had radial cracks in the bottom which were through wall (Figure $8 \mathrm{~B}$ ) similar to the sidewall cracks.

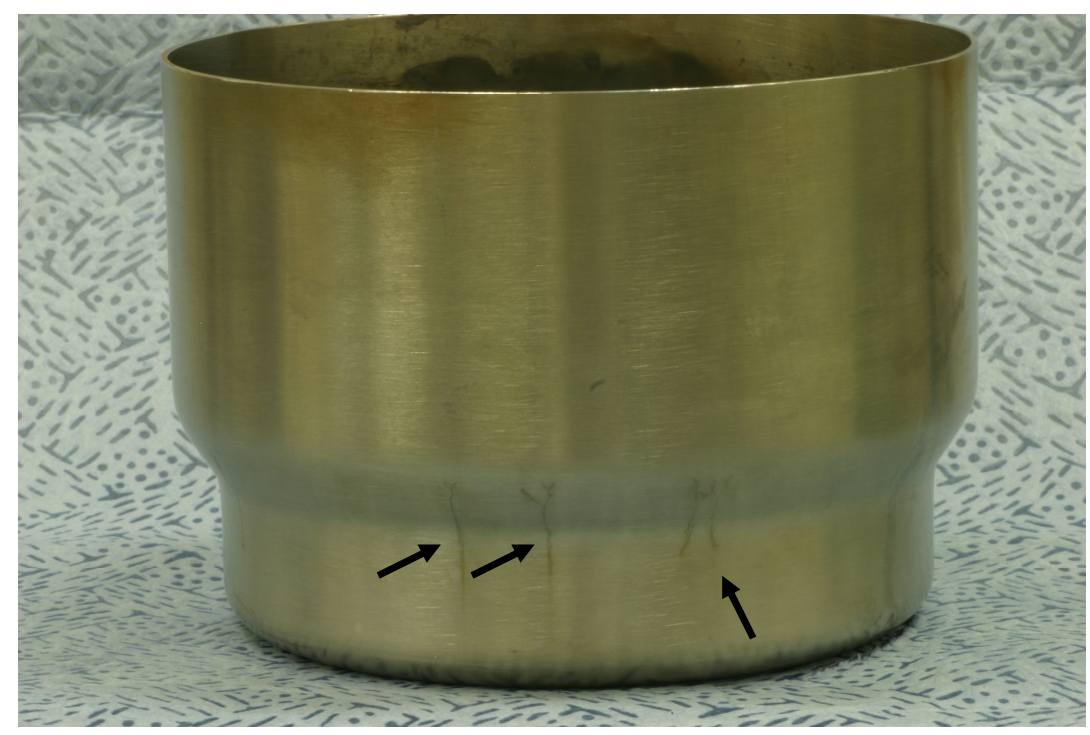

(A)

Figure 8A. SRS Convenience can after exposure to boiling magnesium chloride solution: can exterior with axial cracks in sidewall. Arrows indicate the cracks. 


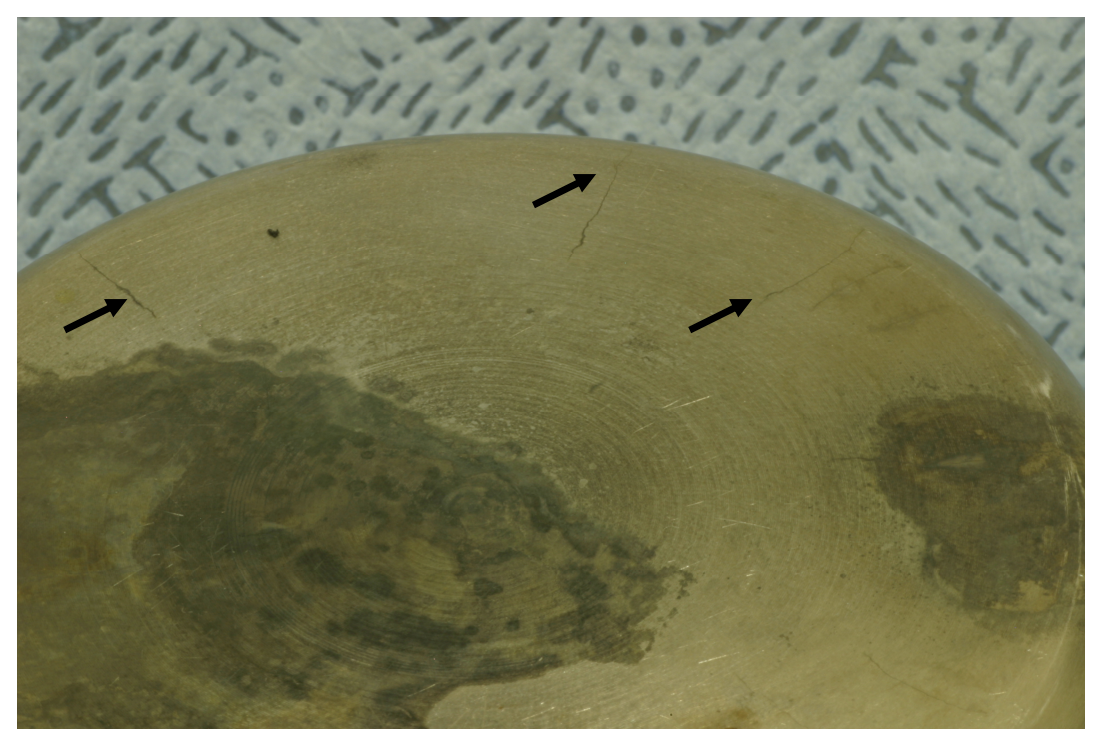

(B)

Figure 8B. SRS Convenience can after exposure to boiling magnesium chloride solution: can exterior bottom with radial cracks. Arrows indicate the cracks.

\subsection{L TEARDROPS}

In 2008, 304L teardrops with autogenous welds were exposed, during the small scale corrosion testing in SRNL to plutonium-oxide-bearing material with $0.2 \%$ calcium chloride at room temperature and were found to crack after 166 hours of exposure [7]. The relationship of corrosion susceptibility of these teardrops to flow formed 304L cans has not been established. As a measure of this relationship, identical teardrops to those used in the small scale test were also tested in boiling magnesium chloride solution. The teardrops failed after approximately 1.3 hours of exposure with a full-width through wall crack (Figure 9). The crack was near the weld but outside the heat affected zone.

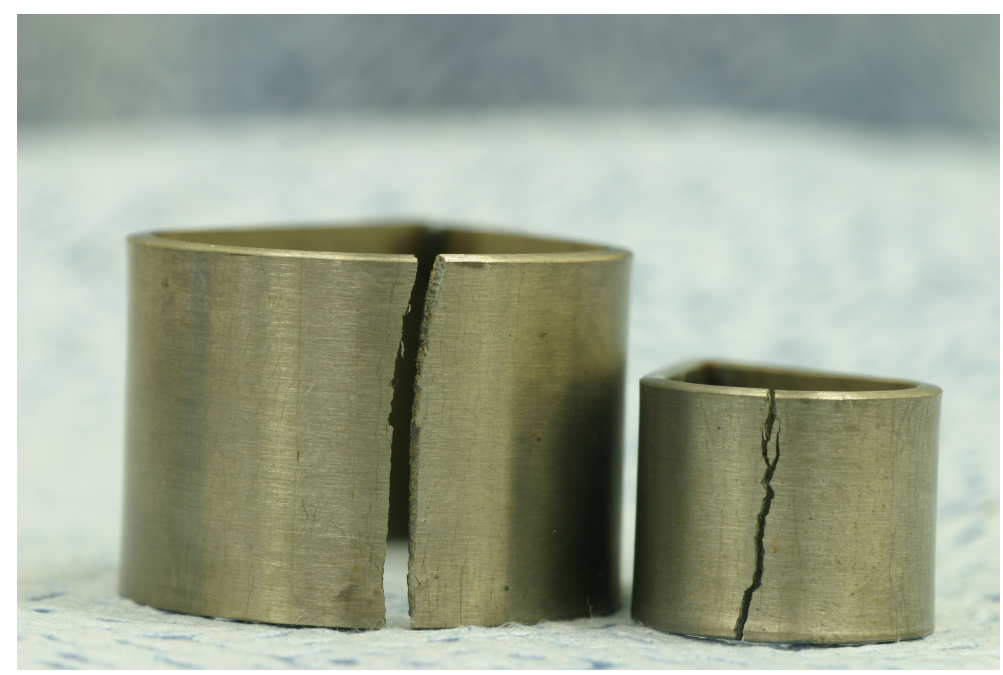

Figure 9. 304L teardrops after exposure to a boiling magnesium chloride solution. 
Numerous surface cracks, which were oriented across the width of the teardrop, were found along the entire length except near the weld that held the ends of the teardrop. Teardrops without the autogenous weld were also found to fail in a similar manner but after slightly longer times, approximately 1.6 hours. A small-sized teardrop ( 0.5 ' width, 2.5 ' length, 0.0625 " thick) was also tested since this type sample was under consideration for use during the next phase of small scale testing. The teardrop failed after approximately 2 hours with a through wall crack at a similar location to the cracks in the large teardrops (Figure 9).

\subsection{CALCIUM CHLORIDE TEST RESULTS}

A $40 \%$ calcium chloride solution at $100{ }^{\circ} \mathrm{C}$ was used to test both an inner can top and $304 \mathrm{~L}$ teardrops for SCC susceptibility in an environment that is less aggressive than boiling magnesium chloride. Literature data for 304L stressed coupons showed cracking within 144 hours [8], which was significantly longer than the current result of approximately 1.5 hours in the boiling magnesium chloride.

\subsection{INNER CAN - WELDED TOP}

The test with the inner can welded top was performed for approximately 84 hours. The can had not cracked after 24 hours in test, but was cracked in a similar manner to the boiling magnesium chloride at 84 hours. The inner can top cracked quickly (2-4 hours) in the boiling magnesium chloride solution. Multiple cracks grew perpendicular to the weld in the sidewall (Figure 10). The cracks were approximately 5-7 $\mathrm{mm}$ in length as measured macroscopically on the exterior sidewall. Many of these cracks were through wall. Cracks were also found in the top plug but only two were suspected to be through wall. These cracks appeared shorter in length. No further evaluation of the cracks was performed on this can.

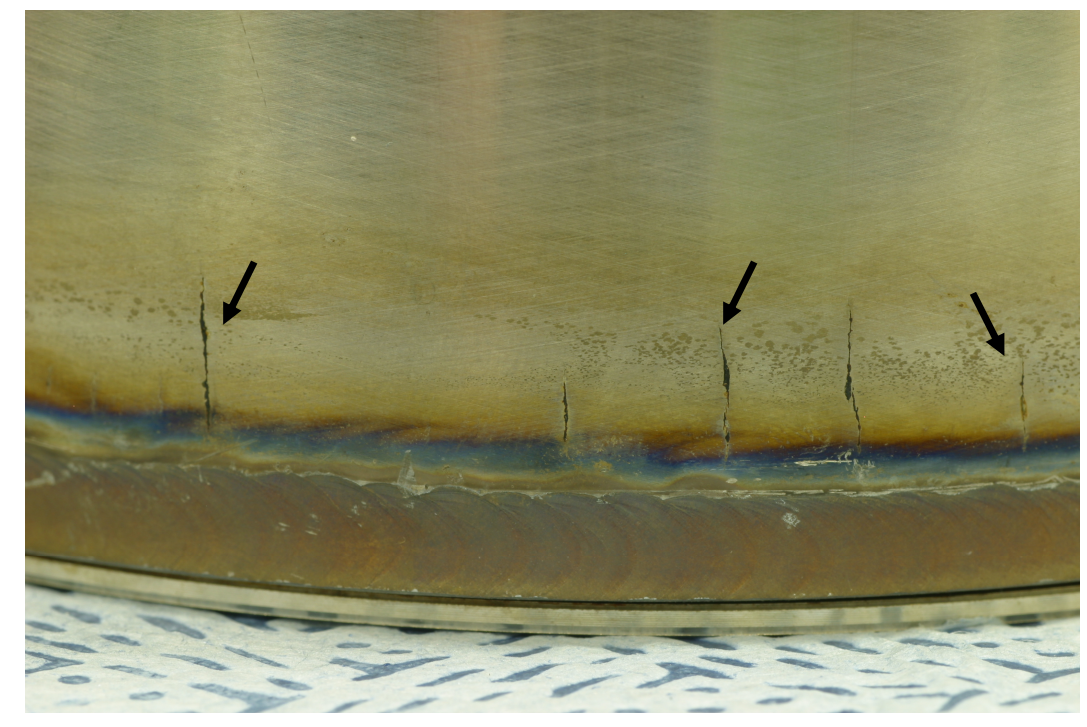

Figure 10. 3013 inner cap welded top tested a with 40\% calcium chloride solution at $100^{\circ} \mathrm{C}$. Arrows indicate cracks. 


\subsection{L TEARDROPS}

A series of both the standard and small-sized teardrops were exposed to the calcium chloride solution with periodic removals during the course of the test. The initial plan was to obtain an average crack growth rate. The test was run for 220 hours. The first samples, both a standard and small-sized, were removed at 118 hours and found to have multiple cracks which were located primarily along the bottom of the teardrop near the autogenous weld. The amount of cracking increased with time as cracks appeared to generate farther from the weld along the length of the teardrop (Figure 11, page 15). The cracks were also highly branched. Determination of a crack growth rate was not possible because of the multiple cracks that formed. The teardrops in the vapor space region showed minimal degradation with a few spots of discoloration. Cracking was found on both a standard and small-sized teardrop exposed to the vapors only (Figure 12).

The corrosion potential of the teardrops was followed with two teardrops, one standard and one small, which had wires attached for the monitoring signal. The potentials of the two different size teardrops were similar. The initial potentials were approximately $-425 \mathrm{mV}$ and over the course of the test drifted to $-0.375 \mathrm{mV}$. No big change in potential was observed to signify cracking since many small cracks were generated. The small crack openings would not cause a significant change since the teardrops surface areas were much larger than the fresh surface of an opened crack.

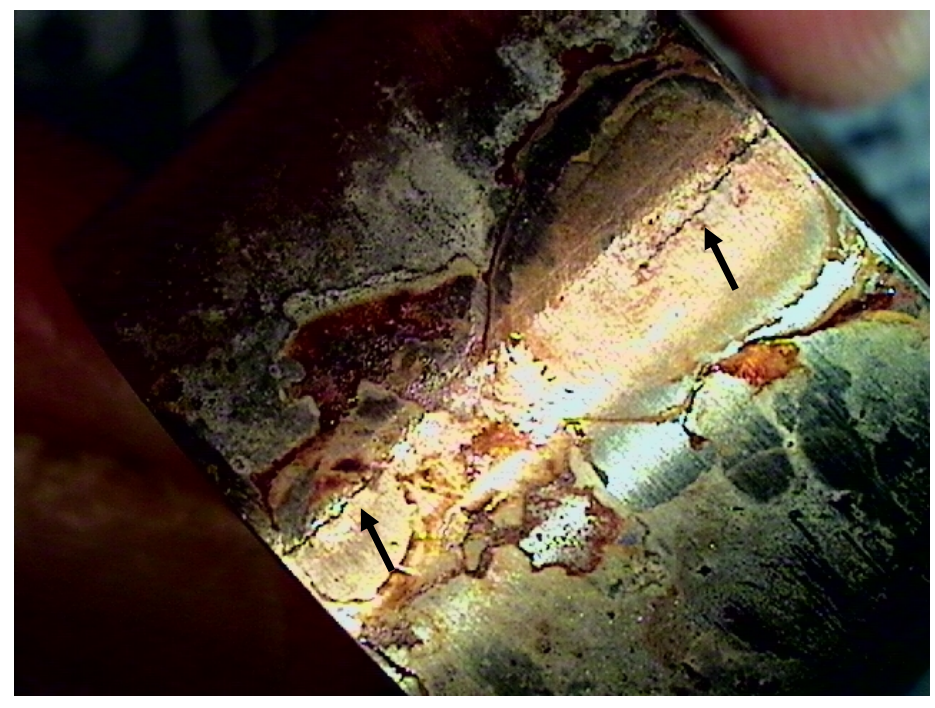

Figure 12. 304L Teadrop with cracks after exposure to the vapors from a $40 \%$ calcium chloride solution at $100^{\circ} \mathrm{C}$. Arrows indicate cracks. 


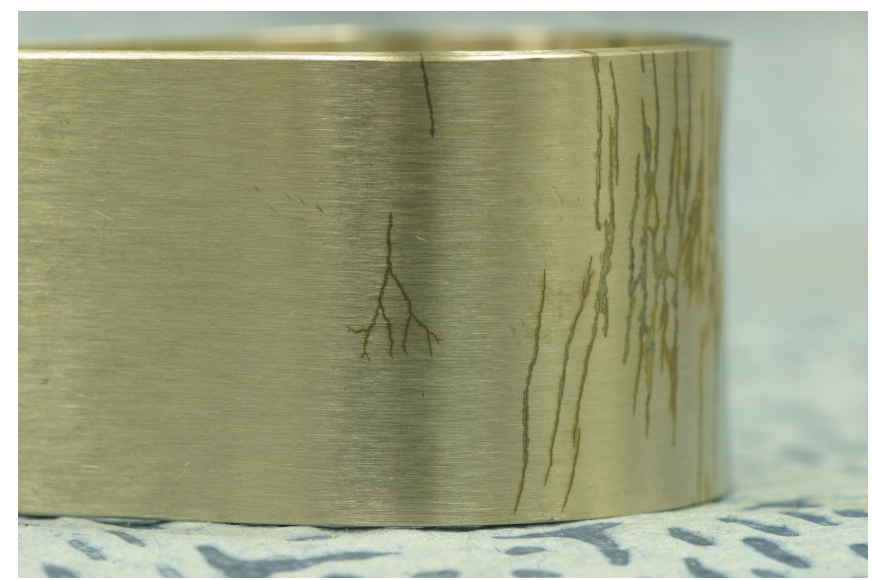

(A)

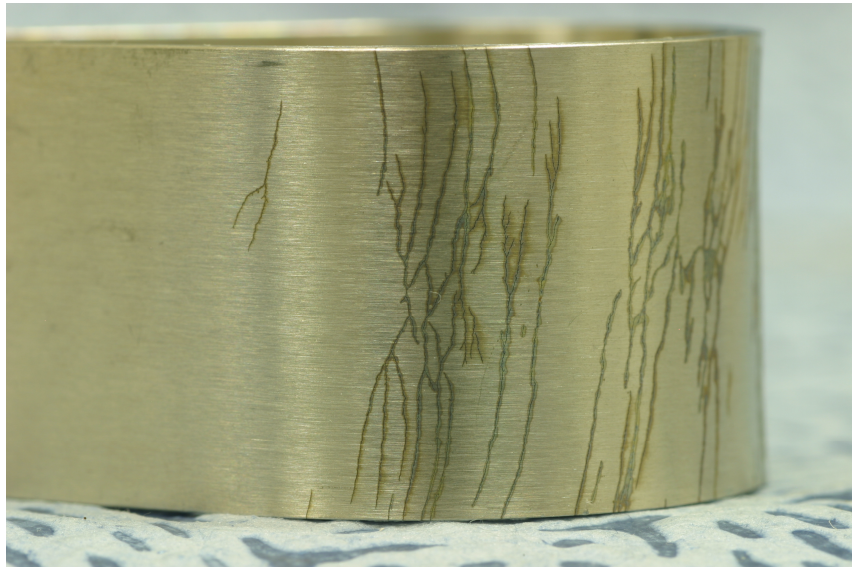

(B)

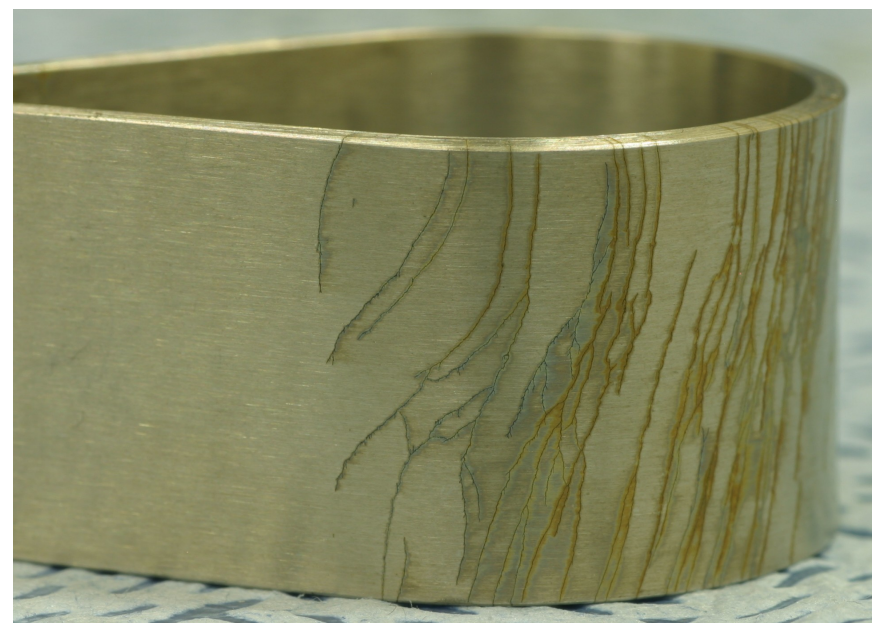

(C)

Figure 11. 304L Teadrops tested in $40 \%$ calcium chloride solution at $100{ }^{\circ} \mathrm{C}$ for: (A) 188 hours; (B) 194 hours; and (C) 220 hours. 


\subsection{DISCUSSION}

The 3013 cans all had sufficient residual stresses to crack in the boiling magnesium chloride solution. Time to failure in these solutions is inversely related to the level of residual stress [9]. The 304L teardrops had the shortest time to failure in approximately 1.3 hours and therefore provide a conservative estimate for the 3013 cans. The stress levels in a teardrop have been shown to exceed the yield stress and approach levels equivalent to the ultimate tensile strength [10].

By comparison the inner can welded top failed in a time as short as 2 hours, which indicates a lower residual stress in the weld than the stresses in the teardrop. The other inner can welded top was tested for 3.5 hours and had a more significant degree of cracking with a circumferential crack running parallel to the weld. The perpendicular and parallel cracking near the weld indicate a complex stress state in the weld region (Figure 5). The inner can bottom appears to have lower stress levels resulting from the can fabrication since the degree of cracking is less (i.e. smaller number of through wall cracks) and the time to cracking is greater (i.e. one can tested for 48 hours had no cracks in the sidewall).

The time to cracking for the convenience cans may be variable. After 5.5 hours the SRS can leaked so cracking had occurred in times approaching that for the inner can welded top. The Hanford can did not leak during the test so time to cracking is unknown. Fabrication stresses for at least the SRS convenience can is approaching those resulting from welding but is clearly less.

Additionally the inner can welded top cracked in the vapors of the boiling magnesium chloride solution. The cracks were small and not through wall, but extended exposure beyond the five-day test period would probably have resulted in similar cracking to those can tops exposed directly to the boiling magnesium chloride solution. These results show that the residual stresses are sufficient to cause cracking when chloride-containing vapors condense on the stainless steel surface.

The results from the calcium chloride test showed that that cracking will occur in the 3013 cans in less severe environments than a boiling magnesium chloride solution, and as expected the time to cracking is significantly longer. Testing was conducted with only the inner can welded top but similar results would be expected for the convenience cans and inner can bottom. The cracking morphology was similar, i.e. short perpendicular cracks to the weld. Cracking also is possible in the vapor space of such environments since cracking occurred in the $304 \mathrm{~L}$ teardrops exposed to the vapor of the $40 \%$ calcium chloride solution. The vapor space cracking was significantly less than that observed on teardrops immersed in the solution. Crack growth could not be determined for the immersed teardrops since multiple cracks initiated.

Time to failure for the teardrops and the inner can top can not be compared since the cracks were detected after initiation. Literature data suggested that cracking would take approximately 144 hours for teardrops [11], but for this testing, cracks were found to have 
initiated by 84 and 118 hours for the can and teardrops, respectively. This difference may be associated with the definition of cracked or experimental set up. Details of the testing were not provided in the literature.

\subsection{CONCLUSIONS}

Testing of the 3013 inner and convenience cans has shown that sufficient residual stresses exist at both the inner can closure weld and in sections of the cans where the can diameter changes, i.e. near the can bottom. Cracking was found to occur sooner in the inner can welded top than the can bottom of either the inner or convenience can. This shorter time is indicative of higher residual stresses from welding than fabrication. Additionally, microstructure in the HAZ is likely to provide an added component for pitting corrosion and SCC. Teardrop samples are a conservative marker for the cans since failure in the boiling magnesium chloride test occurred in even shorter times than the welded top. Cracking from the condensed vapors of both the hot calcium chloride and boiling magnesium chloride solutions occurred, so SCC may be a plausible mechanism for the 3013 cans if a thin chloride-bearing film forms above the oxide/salt mixture. The chloride concentration in the 3013 cans is expected to be a small fraction of those used in this testing.

\subsection{ACKNOWLEDGEMENTS}

The author would like to acknowledge the talented assistance of Karen Hicks in conducting the experimental work and Dr. Mac Louthan, Jr. for helpful discussions. 


\subsection{REFERENCES}

1. D. G. Kolman, "A Review of the Potential Environmentally Assisted Failure Mechanisms of Austenitic Stainless Steel Storage Containers Housing Stabilized Radioactive Compounds," Corr. Science, Vol. 43, 99-125, 2001

2. Test Plan for Determining the Susceptibility of 3013 Containers to Stress Corrosion Cracking, 2009

3. ASTM G36-94 (Reappproved 2006), Standard Practice for Evaluating Stress Corrosion Cracking Resistance of Metals and Alloys in a Boiling Magnesium Chloride Solution, ASTM International, West Conshohocken, PA

4. K. A. Dunn, "Residual Stress Testing of Outer 3013 Containers (U)," WSRC-TR2002-00396, Rev. 0, August 2003

5. L.-Z. Jin, "The Chloride Stress Corroison Cracking Behavior of Stainless Steels under Different Test Methods," J. Mat. Eng. and Perf., Vol. 4(1), 734-739, 1995

6. ASTM G123-00 (Reappproved 2005), Standard Test Method for Evaluating Stress Corrosion Cracking of Stainless Steel Alloys with Different Nickel Content in Boiling Acidified Chloride Solution, ASTM International, West Conshohocken, PA

7. P. E. Zapp and J. M. Duffey, "Status Report for SRNL 3013 Corrosion Tests (U)," WSRC-STI-2008-00046, Rev. 0, August 2008

8. Sandmeyer Steel Company, Specification Sheet for 304 Stainless Steel

9. O. M Alyousif and R. Nishimura, "On the Stress Corrosion Cracking and Hydrogen Embrittlement of Sensitized Stainless Steel in Boiling Magnesium Chloride Solutions Effect of Applied Stress," Vol. 50, 2919-2926, 2008

10. P. S. Lam, "Initial Stress in Tear Drop Corrosion Specimens (U), " SRNL-MST2008-00032, February 14, 2008

11. www.sandmeyersteel.com, Stress Corrosion Cracking - 304L, 2008

12. D.K. Veirs, "Summary of temperature and relative humidity information for evaluation of the possibility of stress corrosion cracking in 3013 containers," LA-UR08-05900, 2008 